\title{
Publisher Correction: Biological classification of childhood arthritis: roadmap to a molecular nomenclature
}

Peter A. Nigrovic, Robert A. Colbert, V. Michael Holers, Seza Ozen (D, Nicolino Ruperto (D), Susan D. Thompson (D),

Lucy R. Wedderburn (D), Rae S. M. Yeung (D) and Alberto Martini (D)

Correction to: Nature Reviews Rheumatology (2021) https://doi.org/10.1038/s41584-021-00590-6, published online 17 March 2021.

In the originally published version of this article, the CLUSTER Consortium was incorrectly described as "the Consortium Linking Universities of Science and Technology for Education and Research (CLUSTER)". The incorrect definition of CLUSTER has now been removed in the HTML and PDF versions of the manuscript.

https://doi.org/10.1038/s41584-021-00610-5 I Published online 29 March 2021

(C) Springer Nature Limited 2021

\section{Publisher Correction: Cardiovascular effects of approved drugs for rheumatoid arthritis}

\author{
Fabiola Atzeni, Javier Rodríguez-Carrio, Călin D. Popa, Michael T. Nurmohamed, Gabriella Szúcs and Zoltán Szekanecz
}

Correction to: Nature Reviews Rheumatology (2021) https://doi.org/10.1038/s41584-021-00593-3, published online 8 April 2021.

In the originally published version of this article there was an error in figure 3 . In part b, the colours of the red and green circles within the table were erroneously reversed. The figure has been corrected so that the red circles represent pro-atherogenic effects and the green circles represent anti-atherogenic effects. This error has now been corrected in the HTML and PDF versions of the manuscript.

https://doi.org/10.1038/s41584-021-00616-z I Published online 16 April 2021

(c) Springer Nature Limited 2021 